\title{
Study on Occupancy Behaviors of Passengers in the Subway Cabin: An Observation in Chengdu, China
}

\author{
Si-Jun He 1 and Jin-Yi Zhi $(D)$ \\ School of Design, Southwest Jiaotong University, Chengdu 611756, China \\ Correspondence should be addressed to Jin-Yi Zhi; zhijinyi@swjtu.edu.cn
}

Received 21 June 2021; Revised 11 December 2021; Accepted 27 December 2021; Published 19 January 2022

Academic Editor: Arkatkar Shriniwas

Copyright ( $\odot 2022$ Si-Jun He and Jin-Yi Zhi. This is an open access article distributed under the Creative Commons Attribution License, which permits unrestricted use, distribution, and reproduction in any medium, provided the original work is properly cited.

\begin{abstract}
Insufficient attention has been paid to how subway cabins are used by passengers and especially the distribution of passengers and occupancy of facilities. In this study, passengers were observed in 133 sections from the beginning to the end of the early peak of Chengdu Metro in the working days. The differences in occupancy behaviors of passengers to different areas, seats, and standing auxiliary facilities in the cabin were analyzed by the nonparametric test. The occupancy curve was fitted by the least square method from the minimum to the maximum load factor, and the prediction and explanatory model for the use of cabin was established. As expected, the distribution of passengers in the cabin is uneven. The highest occupancy rate has been maintained at the cabin end. Female passengers accounted for the largest proportion in the door area, while male passengers accounted for a larger proportion at the end of the cabin. There is no difference in the use of different seat types by passengers. There are more seats in female passengers, and females are more likely to get the remaining seats when the seat load is nearly saturated. For the auxiliary standing facilities, there are always passengers who do not use the facilities and the proportion is increasing. The facilities that can be relied on account for a greater median proportion of the passengers with facilities, but service capacity is limited. In response to these conclusions, measures to improve the design of the cabin are proposed.
\end{abstract}

\section{Introduction}

The subway has been in operation in 57 countries and 178 cities in the world, and all the top 10 cities in China's passenger volume have exceeded the international average passenger volume [1]. Ridership of the subway by passengers is a hot topic in the field of transportation and travel. Recent research has discussed the behavior of passengers with respect to avoiding the peak time [2], waiting on the platform [3], boarding and alighting [4,5], emergency behavior in subway accidents $[6,7]$, and even suicide in the subway $[8,9]$. However, there are only few studies focusing on the behavior of passengers after boarding. Wardman et al. [10] and Evans et al. [11] investigated the preferences of passengers for seat positions and published important insights in this field. There is still a lack of research on observing all passengers in one cabin as objects [12]. Since each person's position is fixed in planes [13], trains [14], buses [15], and cars [16], it is feasible to investigate the individual passenger's behavior. However, since passengers are allowed to stand and freely change positions in the subway cabin, passengers standing in the subway also need to be paid attention to in addition to those who are seated, and they are also included in the rated number of passengers on the subway together with those seated. The maximum allowable passenger density at peak of New York Metro is 2.6 pass $/ \mathrm{m}^{2}$, $1.8-2.4$ pass $/ \mathrm{m}^{2}$ for Toronto Metro [17], and 5 pass $/ \mathrm{m}^{2}$ for London Metro [18]; the standard in China is $6-9$ pass $/ \mathrm{m}^{2}$ [19]. It is generally considered that 6 pass $/ \mathrm{m}^{2}$ is the acceptable critical limit for the absence of apparent discomfort to passengers $[20,21]$. Although standards vary from region to region, it is certain that passengers standing in the subway are sometimes far more than those in seats, especially during the peak periods [22]. Therefore, it may be more helpful for 
service promotion to study the behaviors of group passengers than the preference of individual passengers in the subway cabin.

It is generally accepted that crowding depends on the dual dimensions of available physical space and psychological perceptions of passengers $[23,24]$. In quantitative assessment, it is a standard method to describe the crowding level in the cabin by passenger density, occupancy, or load factor $[25,26]$. However, crowding is rarely connected with the interior design of the cabin, and the existing research focuses on the door area to improve the boarding and alighting efficiency of passengers [27-31]. These studies are necessary, but there is no investigation into the use of the area and facilities after boarding. It is considered ideal that passengers are evenly distributed in the cabin [32] and all have facilities to use, but is that true? To this end, we conducted this research with the following objectives:

(i) To investigate the use load of one cabin in the complete driving section

(ii) To investigate the occupancy of areas, seats, and auxiliary facilities in the cabin by passengers under different loads

(iii) To compare the differences in occupancy behaviors of passengers of different genders

(iv) To identify the influence of cabin design on passenger behavior and accordingly propose strategies for future improvement

\section{Literature Review}

Unified technical standards are being developed for China's metro trains, including the interior design of cabins. According to data of China Urban Rail Transit Association in 2019, a total of 6,966 vehicles (six cabins for each vehicle on average) have been allocated, and the annual passenger volume has reached 26.455 billion passengers, serving the most passengers in the world. There are very few literatures that focus on how the cabins are used by passengers, especially those standing in the cabin. These literature studies are shown in Table 1 and illustrate the differences with the objectives of this study.

2.1. Load of the Cabin. Although the parameters used to describe the occupancy of cabin capacity are different in different regions of the world, they can be summarized in two ways: area-based and seat number-based. It is useful to define the standing area, which measures the load on the current cabin based on the number of passengers allowed to stand. The load factor is typically defined as the ratio of passengers to the number of seats. Wardman and Whelan [23], on the other hand, believe that the density of standing passengers is a better indicator of load because the number of seats varies greatly between trains. The way loads are described based on standing density and seat load is listed in Table 2.

PIXC is a percentage parameter used by London underground to measure when the recommended load (5 pass/ $\mathrm{m}^{2}$ ) is exceeded. In practical applications, the peak PIXC in the morning and afternoon peak hours is used to measure the cabin load on that day. When the recommended load is reached, the corresponding peak PIXC score is generally about $40 \%$ [37]. However, in the multiple observations during the peak period of the working day, the single cabin load is generally $3.0-4.5 \%$ of the peak PIXC [38]. Li and Hensher's [38] survey of Melbourne and Sydney found that rail authorities used the average load of standing at multiple stations to monitor the congestion level of the railways is too aggregate. O'Malley and Vaishnav [14] also observed the cabin load. They collected 50 observations in the Chicago subway, but only the 10 times with the highest load were analyzed. Tirachini et al. [39] suggested that it should be regarded as crowded when it exceeds $80 \%$ of the seat load. Berkovich et al. [12] observed the New York subway and found that when the overall load rate of the cabin exceeds $120 \%$, the load rate of the seat can exceed $90 \%$.

We state these studies to illustrate that the advantage of calculating the cabin load is that it can quantitatively evaluate the usage of the cabin. Although there is no unified measurement standard, it is easy to convert between the load rate and passenger density. When observing the cabin load, some studies will collect statistics at a fixed time, usually during the peak period, but the selection of cabin is random. As a result, there is a lack of continuous data for the same cabin across the entire travel range. For the vast majority of passengers, taking the subway is a continuous process that often involves multiple stations, and the load inside the cabin is constantly changing.

2.2. Passengers' Behavior in the Cabin. The configuration and occupancy of seats cannot be ignored in public transport. The service capacity of seats in the subway is limited, and passengers strive to get seats as soon as possible after entering the cabin [18]. It has been found that passengers have obvious preference for seats by the window and in the same arrangement rather than face-to-face arrangement and the middle one of the three seats. Standing is also an important choice for passengers when facing high-load cabins or disliking the seating layout [10]. O'Malley and Vaishnav [14] concluded only $22 \%$ people like the longitudinal seating layout, which means that the transverse seating layout is more popular than the longitudinal one. Berkovich et al. [12] found that there is no gender difference in passengers' choice of seats, and passengers standing in the cabin prefer to gather in the door area, but this study only observed noncrowded cabins.

Many passengers choose to stand at a location where they can keep sufficiently away from others even if there is a vacant seat [11], and there are other factors that cause standing, including nonavailability of a clean location, selecting the door area or the two ends in case of crowding, or ventilation and safety reasons [18]. The sense of insecurity and discomfort will increase as the passenger density increases in the cabin [25], and the passenger density in the door area is an important factor affecting the boarding and alighting of passengers. Puong [40] concluded that the 
TABLE 1: The primary literature on the cabin's interior use.

\begin{tabular}{|c|c|c|c|c|c|}
\hline Literature & Object & Method & $\begin{array}{l}\text { Attributes of focus } \\
\text { on }\end{array}$ & The main point of view & $\begin{array}{l}\text { The distinction between } \\
\text { research objectives }\end{array}$ \\
\hline
\end{tabular}

(i) Railway passengers prefer $2+2$ seats rather than $3+3$ or longitudinal seats.

Focus groups, SP

[10] British rail train video-based $\mathrm{RP}$ surveys

Take snapshots inside the cabin (ii) In crowded cabins, $2+2$ seats in the same direction questionnaires, and
Choice of seat and standing position
Passengers' preference for seat layout are more popular than faceto-face seats.

(iii) People do not like seats with their backs to the direction of travel.

(iv) Thirty percent of the observation samples chose to stand.

(i) People do not like the seat near the support post, preferring the seat by the window.

(ii) As the load increases, men are more likely to stand up.

(iii) Asymmetric doors contribute to the even distribution of standing passengers.

(i) The first is to actively get seats, especially the position by the window.

(ii) When it is determined that the cabin is crowded, passengers will choose to stand near the door rather than moving to the middle. (iii) Even when there are seats, some passengers will choose to stand because of hygiene and other factors.

(i) Transverse seats are not recommended in the hall.

(ii) Vertical handrails provide stability for more
Metro vehicles in Focus group method, Stockholm, Melbourne, and Rio de Janeiro on-site questionnaire, and station observer
The effect of cabin design on passenger detention people than the handrails at the top.

(iii) It is necessary to provide a standing area by reducing seats. seat preferences took into account almost all seat layouts on British trains. However, standing passengers do not need to be considered in the survey of traditional trains.
A comprehensive survey of

The peak hour was avoided, and the survey was conducted only in uncrowded cabins, and the behavior differences under different seat load coefficients were described. Similarly, the extent of these differences was not reported.

Although field observers were deployed, the main purpose was to correct the bias caused by the focus group method. Only descriptive written records were made, lacking quantitative information.

The view was expressed that passenger growth should be addressed by changing the design of the cabin. The acquisition of data is based on the subjective attitude of passengers, and the objective data is the dwelling time of the train. The load conditions of the cabins were not reported.

(i) Severely crowded spaces include the front hall of the carriage and the platformcarriage interface.

(ii) Crowding reinforces negative emotions.

(iii) Placing the hand on the overhead crossbar for a long time causes discomfort.
Qualitative research methods were used. The unselfconscious behavior of passengers was recorded by the observation method. 
TABLE 1: Continued.

\begin{tabular}{|c|c|c|c|c|c|}
\hline Literature & Object & Method & $\begin{array}{l}\text { Attributes of focus } \\
\text { on }\end{array}$ & The main point of view & $\begin{array}{l}\text { The distinction between } \\
\text { research objectives }\end{array}$ \\
\hline$[34]$ & Australian railway & Focus group method & $\begin{array}{l}\text { Passenger behavior } \\
\text { during peak hours }\end{array}$ & $\begin{array}{l}\text { (i) The poles and handrails } \\
\text { are the most effective factors } \\
\text { in improving the } \\
\text { passenger's standing } \\
\text { experience and comfort. } \\
\text { (ii) Hand straps are poorly } \\
\text { accessible and unstable. } \\
\text { (iii) Reasonable design of } \\
\text { the handrail position can } \\
\text { improve the crowded } \\
\text { experience. } \\
\text { (iv) Leaning makes } \\
\text { passengers feel more } \\
\text { comfortable. }\end{array}$ & $\begin{array}{l}\text { A qualitative report on the } \\
\text { attitude of passengers in the } \\
\text { cabin during peak hours. }\end{array}$ \\
\hline$[35]$ & New York subway & Observation record & $\begin{array}{l}\text { Passenger } \\
\text { preference for seats } \\
\text { and standing } \\
\text { positions }\end{array}$ & $\begin{array}{l}\text { (i) Firstly, the transverse } \\
\text { double seats are occupied, } \\
\text { followed by the two ends of } \\
\text { the long seats. } \\
\text { (ii) Standing passengers will } \\
\text { prefer the area near the ends } \\
\text { of the cabin and the pole. } \\
\text { (iii) At high density, } \\
\text { avoidance behaviors such as } \\
\text { facing the wall and crossing } \\
\text { their hands among } \\
\text { passengers will increase } \\
\text { significantly. }\end{array}$ & $\begin{array}{l}\text { The earliest literature on } \\
\text { passenger observation } \\
\text { combined with cabin load. It } \\
\text { is qualitatively described by } \\
\text { observers. }\end{array}$ \\
\hline$[36]$ & Osaka Metro & Observation record & $\begin{array}{l}\text { Differences of } \\
\text { behavior between } \\
\text { male and female } \\
\text { passengers in the } \\
\text { door area of the } \\
\text { cabin }\end{array}$ & $\begin{array}{l}\text { (i) Men raise their arms to } \\
\text { grasp more frequently. } \\
\text { (ii) Men are more likely to } \\
\text { stand facing other people, } \\
\text { while women usually face } \\
\text { the door with their backs to } \\
\text { others. }\end{array}$ & $\begin{array}{c}\text { The behavior of the typical } \\
\text { passenger was observed for a } \\
\text { long time, but there was no } \\
\text { observation of groups. }\end{array}$ \\
\hline
\end{tabular}

TABLe 2: Calculation method of the cabin load.

\begin{tabular}{|c|c|c|}
\hline Measurement basis & Index & Method of calculation \\
\hline \multirow[t]{2}{*}{ Area-based } & Standing load & $\begin{array}{l}\text { The number of standing passengers is divided by the cabin capacity. (The } \\
\text { number of passengers allowed to stand per square meter is multiplied by the } \\
\text { area.) }\end{array}$ \\
\hline & $\begin{array}{l}\text { Passengers in excess of capacity } \\
\text { (PIXC) }\end{array}$ & $\begin{array}{l}\text { The difference between the number of passengers and the capacity of the cabin is } \\
\text { divided by the number of passengers. }\end{array}$ \\
\hline \multirow[b]{3}{*}{ Seat-based } & Seat load factor & The number of passengers is divided by the number of seats. \\
\hline & Seat density & $\begin{array}{c}\text { The ratio of the number of passengers in the same row of seats to the number of } \\
\text { seats. }\end{array}$ \\
\hline & $\begin{array}{l}\text { The percentage of standard class } \\
\text { passengers standing }\end{array}$ & $\begin{array}{l}\text { The method is extended from that of PIXC: the difference between the number of } \\
\text { passengers and the number of seats in the cabin is divided by the number of } \\
\text { passengers. }\end{array}$ \\
\hline $\begin{array}{l}\text { Based on area and } \\
\text { seat }\end{array}$ & Load level at LOS & $\begin{array}{l}\text { The load level of six grades, from A to F, is defined by the seat load factor and per } \\
\text { capita standing area. }\end{array}$ \\
\hline
\end{tabular}

boarding process will be affected significantly if there are more than three passengers in the door area, but the alighting process will not be affected at all. Fernandez [41] found that in a boarding and alighting experiment that simulated the passenger density in the cabin led to longer boarding and alighting times, and it was linear with the boarding time and exponential with the alighting time. Unfortunately, there is few literatures on the occupancy of the remaining space and facilities in high-load cabins. An investigation was conducted into the standing and seat selection behaviors in low-load cabins, and it is believed that passengers have sufficient rights to choose when the load is 
low $[10,12]$. Although the behavior of passengers in highload cabins was observed, the research object was single passengers and lacked a description of group behavior $[18,33-35]$.

The behaviors of passengers of different genders in the cabin are frequently compared. In an emergency, for example, men tend to adopt competitive behaviors, whereas women generally adopt passive strategies to follow the flow of people [6]. In earlier literature, Kobayshi [36] reported the difference in riding posture between men and women in the door area of the cabin. These literatures prompt us to observe the differences between male and female passengers in their choice of cabin location and their use of facilities.

2.3. Influence of Cabin Design. The crowding caused by uneven load among cabins can be solved now [30, 42], but there still is not sufficient attention on local crowding in the same cabin. Tirachini et al. [39] opined that the minimum occupancy rate of the cabin that can trigger discomfort among passengers depends on the culture and characters of passengers and on driving operation and interior design of the subway. Reasonable design of the cabin can guide passengers to flow inward. Coxon et al. [28] studied the influence of different cabin layouts on the dwelling time of passengers in the door area and found that the more the seats that were removed, the shorter the time the passengers stayed in the cabin. Adding seats close to the doors can improve the circulation of passengers; additionally, it was suggested to provide a design that can change the layout of the cabin in different periods of one day. However, Berkovich et al. [12] suggested that seats should not be arranged near the door as far as possible when the passengers are allowed to choose seats in the cabin, which will reduce crowding. In fact, the above studies are not conflicting but based on different load situations. In addition to the seating layout, it has been confirmed that a maximum of $13 \%$ of the boarding and alighting time can be increased if posts are set in the area of the access door [27]. However, Thoreau et al. [29] proved that it has no effect on the boarding and alighting efficiency of passengers whether there is a post near the door. It has also been discovered in experiments in the 1 : 1 cabin model that there is no obvious superiority and inferiority in the influencing passengers' boarding and alighting by the right and left standbacks of the door in different sizes.

Except for the studies on the design to reduce passenger retention, we only found a few surveys on the use of auxiliary standing facilities. Some studies have pointed out that the layout of facilities in the cabin has a nonnegligible effect on improving congestion $[11,34]$. Therefore, helping to improve the design of cabins is also one of the objectives of the study.

2.4. Observation and Research in Public Transport. From the perspective of research methodology, although focus group and questionnaire survey are widely used as a data source for studies on transportation travel $[10,18,28,34]$, the methods based on self-reporting are more suitable to study passengers' attitudes toward public transport services; however, these are considered to lack the objectivity of the group survey [15]. Nonetheless, an observation study can record the actual behaviors of passengers in a specific range [43]. The most intuitive and effective example is that the observers can observe and record the passengers' behaviors in the real cabin $[18,28,33,35,36]$, and a snapshot can be taken in the real cabin [12] or a video can be made in the experimental setting of a built cabin as well $[27,29,31]$. However, its principle is similar to that of arranging observers.

\section{Methods}

Three metro lines in Chengdu were selected for direct observation and recording because the real-time recorded information is more conducive to empirical analysis of the actual choice of passengers rather than the preferences based on survey. The three lines use three general-purpose cabins produced by CRRC (see 3.1 for details). The observation occurred in March 2021 at the early peak of a working day (8: 00-9:00 am) when the observers recorded the standing positions and facilities used by passengers in each driving section from the departure station. It is assumed that the passenger's positions and facilities used are fixed [12]. There are a total of 133 sections and 7,540 heads/time (55.6\% for male and $44.4 \%$ for female) recorded.

3.1. Investigation Subjects. The annual passenger volume of Chengdu Metro is close to 1.5 billion [1]. It ranks 4th in China, comparable to London and Paris subways. According to the data released by Chengdu Metro Operation Co., Ltd., Chengdu Line 2, Line 7, and Line 10 were selected for collecting the data during peak hours, of which Line 2 and Line 7 are the two lines with the largest daily average passenger traffic, and Line 10 is the airport line. The B-type Metro used by Line 2 is the largest stock model in China (Figure 1(a)). It is used for busy lines in some medium-sized cities. The cabin includes standing areas at both ends, four door areas, and three middle areas. The A-type metro used by Line 7 is the model with the largest purchase and export volume of new lines and is used on the trunk lines of major cities (Figure 1(b)). It includes standing areas at one end of the cabin, five door areas, and four middle areas. Line 10 is a hybrid layout model of A-type vehicles (Figure 1(c)), which is gradually used by nonbusy trunk lines.

Each type of cabin includes three types of standing areas, namely, at the ends, the door area, and the middle area along with seven kinds of auxiliary standing facilities (crossbar: the support bar parallel to the roof of the cabin; ring: the handle installed on the crossbar; post: straight rod connecting the floor to the roof; handrail: short handrail installed on the wall or screen; screen: transparent partition on both sides of the seat, which is considered to be an auxiliary standing facility because it is also relied on by passengers frequently; side walls and doors: same as screen). The difference is that the A-type cabin in hybrid layout also has transverse seats, while the other two only have longitudinal seats. Almost all the existing subway cabins contain these design features. 


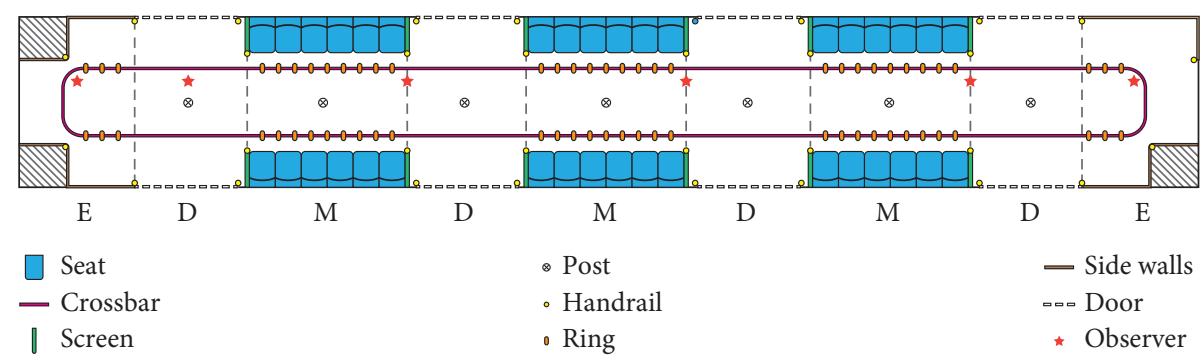

(a)

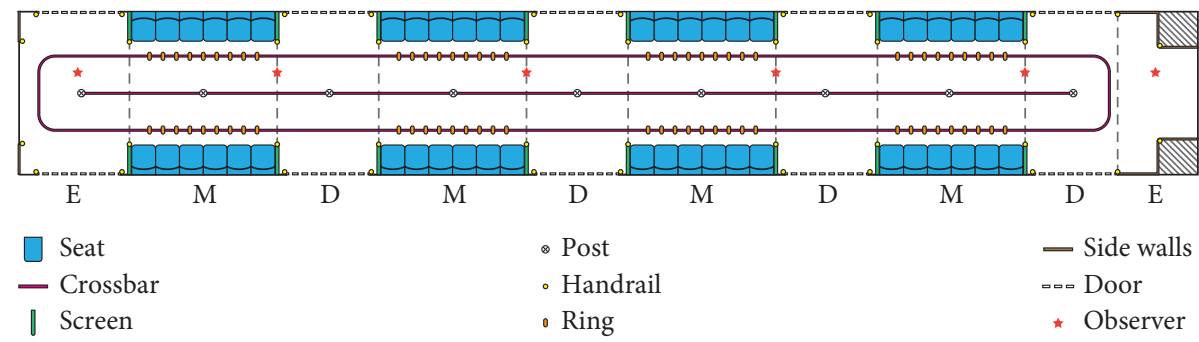

(b)

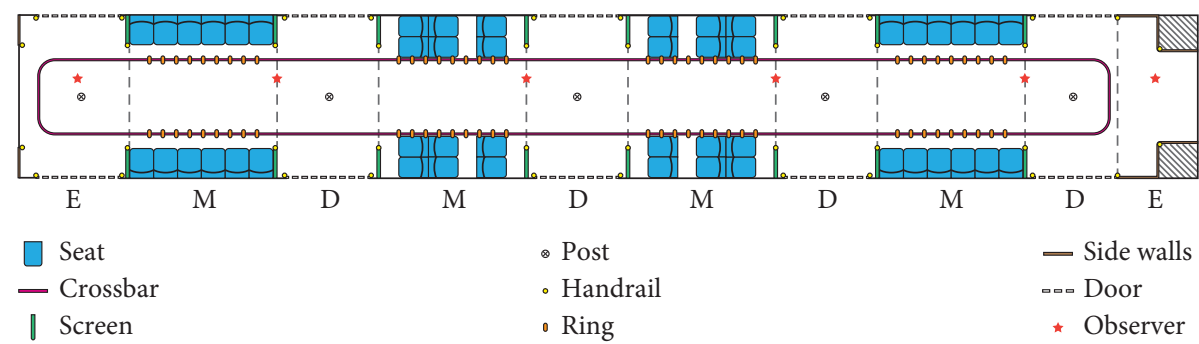

(c)

Figure 1: Schematic diagrams of three types of cabins: (a) B-type metro in longitudinal seating layout, $2.8 \mathrm{~m}$ wide and $19 \mathrm{~m}$ long; (b) A-type metro in longitudinal seating layout, $3 \mathrm{~m}$ wide and $22 \mathrm{~m}$ long; (c) A-type metro in hybrid seating layout, $3 \mathrm{~m}$ wide and $22 \mathrm{~m}$ long. "E" represents the end of the cabin, " $\mathrm{D}$ " the door area, and " $\mathrm{M}$ " the standing area in the middle of the seats.

3.2. Data Acquisition. The first attempt was to record data with snapshots, but it was difficult to avoid the "observer effect" in a narrow space [44] or hide the camera [30]. In the cabin, any visible position is obvious. For the sake of privacy of passengers, it was more appropriate to arrange observers in the cabin. The positions of the observers are shown in Figure 1. Each observer was required to record passenger data in one to two areas. In addition, the same six observers were arranged throughout the observation period to ensure consistency of data collection. For this reason, a template of the size of note paper was developed to classify and record the number of passengers observed in each area (Figure 2). The data collected by six observers was integrated to form the usage record of a complete cabin.

Before the formal investigation, we trained the observers, focusing on explaining the facility classification and the filling method of the forms. Then, several rounds of pretests were conducted during the peak period in order to evaluate the quality of data acquisition and observer load. The pretest required six observers to collect data from the same door area and the middle area. The data was checked after all the sections had been recorded. The results showed that the data of the 6 observers only had errors in the first few stations of the first test, and they only made mistakes in the distinction

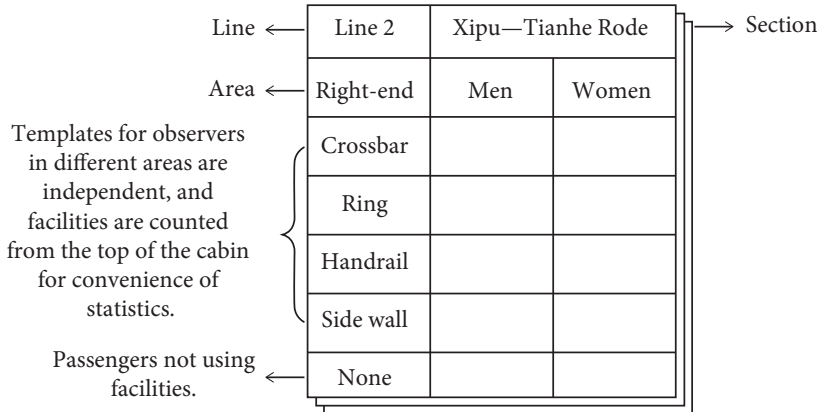

Figure 2: Sample of the record template used by the observers.

of the use of facilities. For example, passengers who leaned on the screen and held the handrails at the same time were included in different categories of facility use. The statistics of the number are correct. Meanwhile, observers believed that there was no time pressure when recording data.

3.3. Data Processing. The ratio of actual passengers to seats is used to describe the occupancy in some countries, but the number of passengers in China is always much greater than the number of seats. Therefore, the capacity of the cabin is 
used as the standard to measure occupancy in this study. The capacity of unit area is calculated according to 6 pass $/ \mathrm{m}^{2}$, and the standard capacity of each area and seat in the cabin is shown in Table 3.

The record of each section was input into Microsoft Excel, and the data was reintegrated according to the observed load rather than the vehicle type. As the design characteristics are the same for all cabins, the interior occupancy of the cabin can be analyzed directly. The calculated capacity occupancy or the proportion of some facilities (areas, seats, and auxiliary facilities) used by passengers was imported into IBM SPSS Statistics 25.0, a statistical software package, for nonparametric testing. The median represents the situation of most sections in the whole line. Then, the curve of the occupancy rate changing with the load factor growth was fitted by the least square method with OriginPro 2021 plotting software, and the regression model of cabin use was established.

\section{Results}

4.1. Cabin Load. As defined by Berkovich et al. [12], the cabin is considered to be under a low load if its overall capacity is less than $40 \%$, under a medium load if in the range from $40 \%$ to $80 \%$, and under a high load if higher than $80 \%$. We believe that low load is an area that can reflect obvious preferences. It has been observed that the maximum cabin load factor is $99.6 \%, M d n=17.2 \%(12.3-31.2)$; the maximum occupancy of standing space is $99.1 \%$, $M d n=11.1 \%(2-20)$; and the maximum occupancy of seats is $105.6 \%, M d n=80.6 \%$ (68.8-97.2). In addition, the growth relationship is fitted (Figure 3) - when the load factor of the cabin reaches $40 \%$, the occupancy of seats reaches saturation (occupancy rate being 100\%) in advance; furthermore, there are always passengers standing in the cabin even when there is a vacant seat.

4.2. Cabin Areas. The occupancy rate of the area is represented by the ratio of the number of passengers and the capacity of the area. It is shown that there is a statistical difference in the occupancy rate of the ends, door areas, and middle areas in the cabin, $x^{2}(2)=64.127, p<0.001$. With pair comparisons made and significance levels corrected by Bonferroni correction, it is shown by the results that the occupancy rate in the middle areas, $M d n=1 \%(0-10.6)$, is significantly lower than that at the ends $(M d n=12.5 \%(5.0-25), z=8.430, p<0.001)$ and that in the door area $(M d n=8(2-22.2) \%, z=6.069, p<0.001)$. There is not a significant difference in occupancy between the door area and the ends $(z=2.334, p>0.05)$. The accurate curve of the occupancy rate of the areas is fitted with the increase of load in the standing space (Figure 4). When the load increases in the standing space, the ends will be occupied first, followed by the door area and the middle area; when the load is close to $75 \%$ in the standing space, the capacity is saturated at the ends and continues to grow; when the load is saturated in the standing space, the middle area is still not filled.
We have established a prediction model to describe occupancy rate of the area through the load at standing space: $A_{i}=b_{0}+b_{1} L . A_{i}$ is the occupancy rate of the area, and $i$ represents the area. $b_{0}$ is a constant term, $b_{1}$ is the regression coefficient, and $L$ is the load at standing space. The complete model of the three areas is shown in Table 4.

The regression model provides more rational evidence for Figure 4. The lower the regression coefficient is, the less influence the increase in load at standing space has on area occupancy, that is, as the total number of standing passengers increases, fewer passengers are allocated to the area.

In addition, an explanatory model was established to explain the mobility of passengers between areas based on the changing proportion of passengers in each area. In the model, $D_{i}=c_{0}+c_{1} L, D_{i}$ is the ratio of passengers in the area to standing passengers, $c_{0}$ is a constant term, and $c_{1}$ is a regression coefficient. The complete model is shown in Table 5.

The regression model for the end of the cabin is nonsignificant $(p>0.05)$, indicating that the proportion of passengers at the end of the cabin does not change as the load at the standing space increases. When the carriages become crowded, the proportion of passengers in the door area decreases, which corresponds to an increase in the proportion of passengers in the middle area (Figure 5).

In order to avoid the interference of difference in the sample sizes of genders, we calculated the proportion of the same gender passengers in different areas. It is shown by the results that there is a significant difference in the proportion of men and women at the ends of the cabin $(z=-1.992$, $p=0.046)$, with more male $(M d n=22.9 \%(0-38.6))$ than female $(M d n=18.9 \%(0-29.7))$; however, the proportion of female passengers in the door areas $(M d n=66.6 \%$ $(52.4-87.1))$ is significantly higher than that of male passengers $(M d n=57.1 \%(50.0-79.6), z=-2.254, p=0.024)$. There is no significant difference between male and female passengers in the middle areas $(z=-0.205, p>0.05)$. The median of passenger proportion only indicates the proportion median of passengers of a certain gender in all sections distributed in this area. The value is determined by the capacity of the area but cannot explain the crowding level, so the passengers are compared in the same area.

4.3. Seats. Figure 3 provides an accurate curve of the relationship between standing space and seat. We try to explain the change in seats and the load at standing space with a more concise model. Use the load at standing space as a dependent variable and the occupancy rate of seats as a predictor variable. The complete model is $L=e_{0}+e_{1} S, e_{0}$ is a constant term, $e_{1}$ is a regression coefficient, and $S$ is the occupancy rate of seats. The results show that the model is statistically significant, $F(1,112)=44.43, p<0.001$. Adjusted $R^{2}=0.30$ indicates that the regression model has a moderate degree of fitness. The detailed model: $L=-0.351+0.658 S$. When the occupancy rate of seats is $100 \%$, the load at standing space is $30.7 \%$.

There is no difference in the occupancy rate of seats caused by different layouts (transverse and longitudinal) and 
TABle 3: Capacity of the cabin.

\begin{tabular}{|c|c|c|c|c|c|c|c|c|}
\hline \multirow[b]{2}{*}{ Vehicle type } & \multicolumn{8}{|c|}{ Capacity (head) } \\
\hline & Ends & $\begin{array}{l}\text { Door } \\
\text { areas }\end{array}$ & $\begin{array}{c}\text { Middle } \\
\text { areas }\end{array}$ & $\begin{array}{c}\text { Seat } \\
\text { (longitudinal) }\end{array}$ & $\begin{array}{l}\text { Seat (by } \\
\text { window) }\end{array}$ & $\begin{array}{l}\text { Seat (along the } \\
\text { passage) }\end{array}$ & $\begin{array}{l}\text { Standing } \\
\text { space }\end{array}$ & $\begin{array}{l}\text { Whole } \\
\text { cabin }\end{array}$ \\
\hline Type-B & 40 & 108 & 66 & 36 & None & None & 214 & 250 \\
\hline Type-A & 16 & 120 & 96 & 48 & None & None & 262 & 310 \\
\hline $\begin{array}{l}\text { Type-A (hybrid } \\
\text { layout) }\end{array}$ & 16 & 120 & 76 & 24 & 12 & 12 & 242 & 290 \\
\hline
\end{tabular}

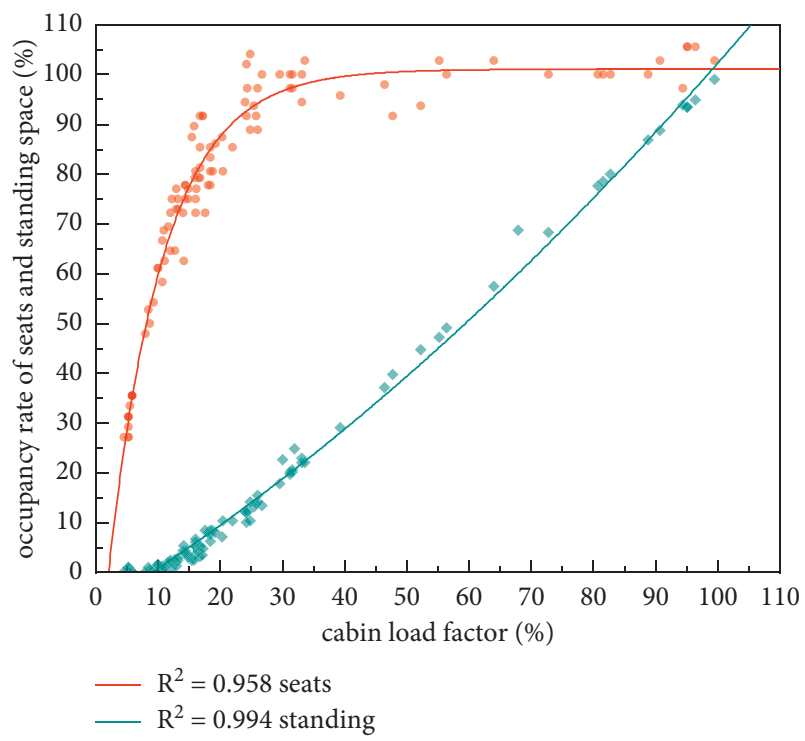

FIGURE 3: Growth curve of the occupancy rate of seats and standing space.

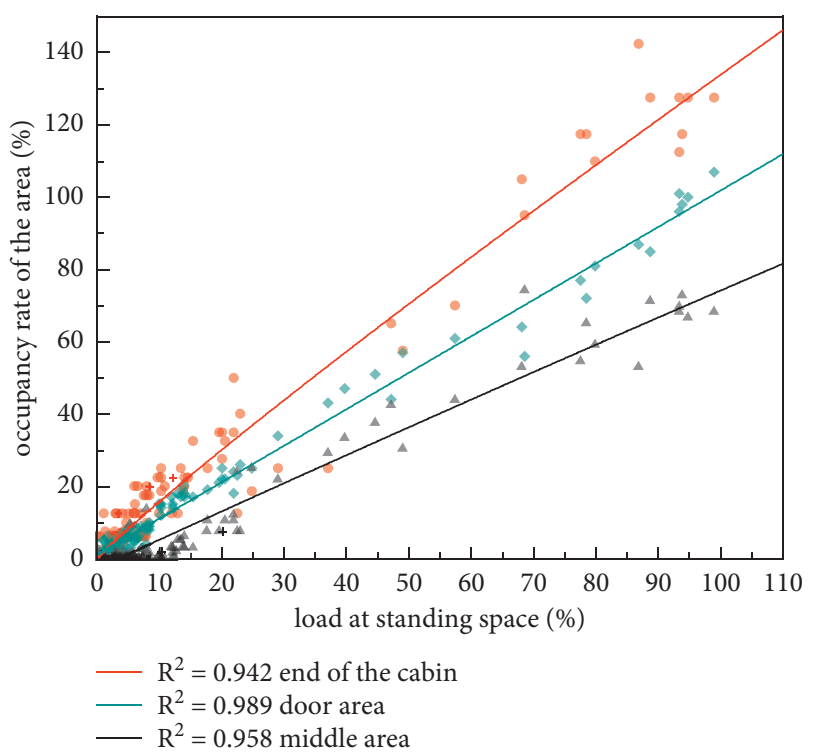

Figure 4: Growth curve of occupancy rates at the ends, door areas, and middle areas.

positions (by window and along the passage) in the cabin in hybrid layout (all $p$ values $>0.05$ ). For the same type of seats, there is no significant difference in the proportion of passengers of a different gender among passengers of the same gender with seats (all $p$ values $>0.05$ ). However, for all the cabin data observed, the proportion of male passengers with seats $(M d n=69.0 \%(40.5-85.0))$ is significantly lower than that of female ones $(M d n=72.7 \%(50.0-92.0), z=-4.776$, $p<0.001$ ). Based on the increase of seat load factor (Figure 6), when the load of seats is lower than 95\%, men get more seats first; when the seat load is saturated or exceeds the capacity, the occupancy rate of seats by female passengers is higher than that of male passengers.

4.4. Auxiliary Standing Facilities. Seven kinds of auxiliary standing facilities are provided for passengers standing in the cabin. The passengers not accessing the facilities are paid more attention because it is more difficult for them to maintain the balance of their body without using any facility. It is obvious that the proportion of passengers in the standing space accessing the facilities $(M d n=83.3 \%$ (70.3-97.5)) is significantly higher than that of those not accessing the facilities $(M d n=16.6 \%$ (2.5-29.7), $z=-8.343$, $p<0.001)$. There is no significant difference in the proportion of passengers accessing and not accessing the facilities between different genders (all $p$ values >0.05). Observing the occupancy rate of facilities (passenger/capacity of standing space) when the load at standing space increases (Figure 7), the slope of the straight line is less than 1 , which indicates that there are always passengers standing and not accessing the facilities.

Similarly, a regression model was established to explain the change in the proportion of passengers with and without facilities (passengers/current number of passengers): $U=k_{0}+k_{1} L, U$ is the proportion of passengers with facilities, $L$ is the load at standing space, $k_{0}$ is a constant term, and $k_{1}$ is the regression coefficient. The fitted graphic is shown in Figure 8. The significance test: $F(1,112)=70.26, p<0.001$, adjusted $R^{2}=0.44$. It shows that the regression model is statistically significant, and the detailed equation is $U=0.893-0.320 L$. That is, as the load at standing space increases, the proportion of passengers with facilities decreases. When the load at standing space reaches saturation, $42.7 \%$ of passengers have no facilities to use.

Furthermore, we compared the proportions of the passengers having no access to the facilities in each area, and there is a significant difference among the three areas $\left(x^{2}(2)=6.260, p=0.44\right)$. Among them, the proportion of the passengers having no access to facilities in the middle $(M d n=20.0 \%(0-31.1))$ is significantly higher than that at the ends $(M d n=13.0 \%(0-35.0), z=2.437, p=0.05)$ and in the door areas $(M d n=12.0 \%(0-29.8), z=2.448, p=0.047)$. 
TABLe 4: Prediction model of passenger occupancy rate of the area.

\begin{tabular}{lcccccccc}
\hline \multirow{2}{*}{$A_{i}$} & \multicolumn{3}{c}{ Regression model } & \multicolumn{3}{c}{ Significance test } \\
& $b_{0}$ & $b_{1}$ & $S E$ & Adjusted $R^{2}$ & $\mathrm{df}$ & $F$ value & $t$ & $p$ value \\
\hline End of the cabin & 0.019 & 1.315 & 0.032 & 0.942 & 112 & 1652.66 & 40.65 \\
Door area & 0.011 & 1.010 & 0.011 & 0.988 & 112 & 8758.80 & 93.58 & $<0.001^{* *}$ \\
Middle area & -0.024 & 0.777 & 0.016 & 0.958 & 112 & 2308.14 & 48.04 & $<0.001^{* * *}$ \\
\hline
\end{tabular}

Note. ${ }^{*} p<0.05 ;{ }^{* *} p<0.01$.

TABle 5: An explanatory model for the proportion of passengers in the area.

\begin{tabular}{lcccccccc}
\hline \multirow{2}{*}{$D_{i}$} & \multicolumn{3}{c}{ Regression model } & \multicolumn{3}{c}{ Significance test } \\
& $c_{0}$ & $c_{1}$ & $S E$ & Adjusted $R^{2}$ & $\mathrm{df}$ & $F$ value & $t$ & 0.238 \\
\hline End of the cabin & 0.230 & 0.016 & 0.066 & 0.001 & 112 & 0.05 & 0.811 \\
Door area & 0.685 & -0.220 & 0.071 & 0.085 & 112 & 9.55 & -3.091 & $0.003^{* *}$ \\
Middle area & 0.085 & 0.205 & 0.061 & 0.099 & 112 & 11.12 & 3.336 & $0.001^{* *}$ \\
\hline
\end{tabular}

Note. ${ }^{*} p<0.05 ;{ }^{* *} p<0.01$.

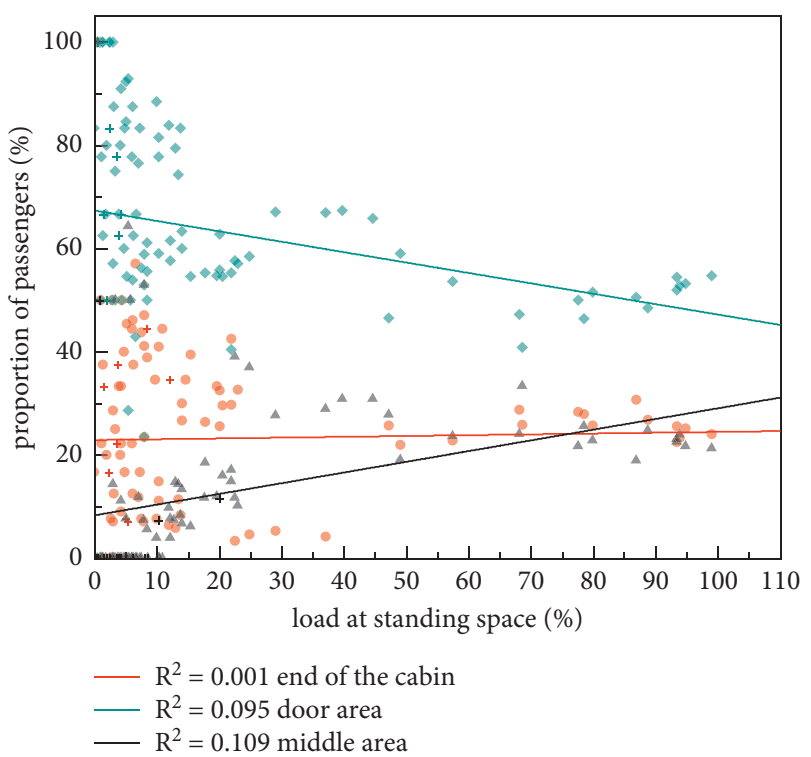

FIgURE 5: Changes in the proportion of passengers in the area.

However, there is no statistical difference in the proportion of passengers having no access to facilities in the door areas and in the ends of cabin $(z=1.174, p>0.05)$.

The proportions of passengers using the seven facilities in all the passengers having access to facilities are as follows: screens $(M d n=25 \% \quad(11.8-33.3))$, posts $\quad(M d n=15.3 \%$ (9.6-25.4)), side walls $(M d n=13.5 \%(7.9-21.3))$, handrails $(M d n=12.5 \% \quad(6.8-20.0))$, rings $(M d n=5.8 \% \quad(0-19.8))$, doors $(M d n=2.7 \%(0-9.5))$, and crossbars $(M d n=0 \%$ $(0-12.5))$. Facilities with high medians are used more frequently. Rings and crossbars are rarely used, but posts and screens, even if only serving limited number of people, are occupied by most passengers.

As it is difficult to define the capacity of the facilities, the occupancy of a certain type of facility is described by its occupancy rate by passengers in the standing space. The accurately fitted curve is shown in Figure 9. When the load factor in the standing space is less than $20 \%$, the posts (Figure $9(\mathrm{c})$ ) and screens (Figure $9(\mathrm{~g})$ ) will be occupied first,

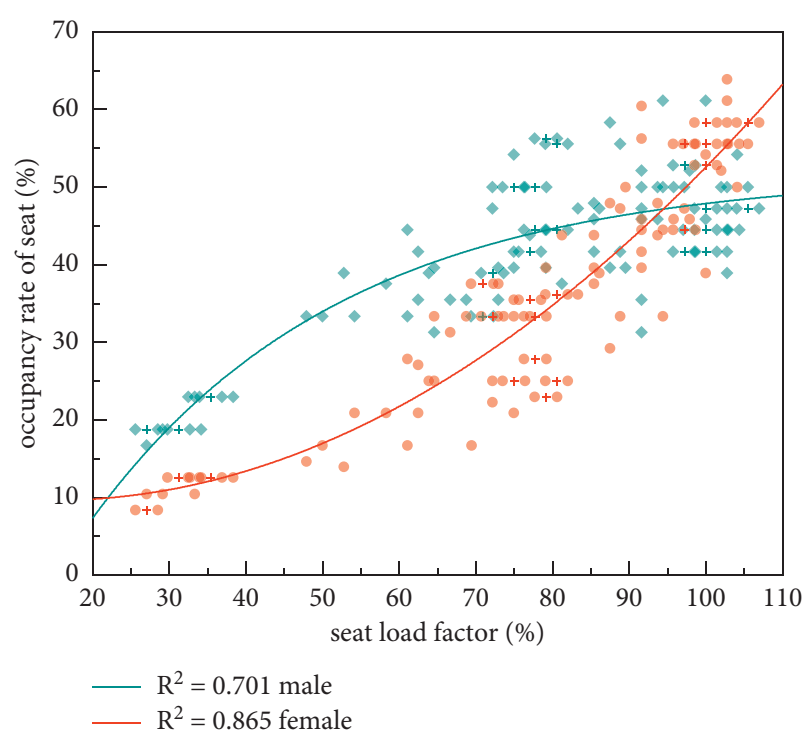

FIGURE 6: Growth curve of seat occupancy rate of male and female passengers.

and the crossbars (Figure 9(a)) and doors (Figure 9(f)) will be occupied least, but passengers have to occupy other facilities with larger capacity when the facilities they like can no longer accommodate more people. When the load is higher than $80 \%$, it can be seen which facilities hold more passengers. At this time, the function of the crossbars and rings (Figure 9(b)) will be fully reflected. Surprisingly, the doors can also accommodate many passengers even if each is labeled with the label "No Leaning." For the convenience of alighting, doors can accommodate more people than the side walls at the ends of the cabin (Figure 9(e)) in case of high load.

The prediction equation of load at standing space on occupancy rate of facility is shown in Table 6. The complete model: $F_{i}=n_{0}+n_{1} L, F_{i}$ represents the occupancy rate of passengers using a certain facility, $n_{0}$ is a constant term, and $n_{1}$ is a regression coefficient. The linear model represents the average growth of facility's occupancy during the entire 


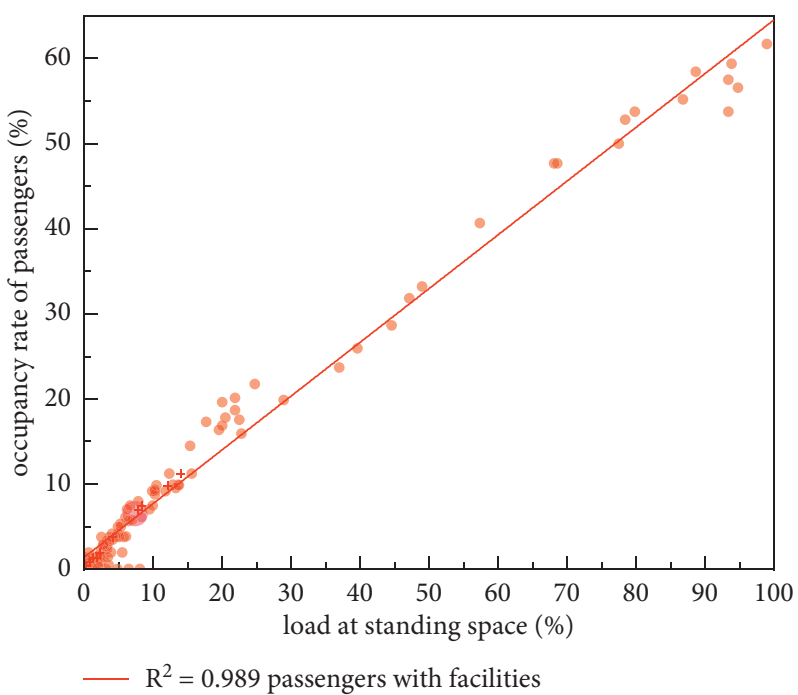

FIGURE 7: Change of the occupancy rate of passengers with facilities to the load at standing space.

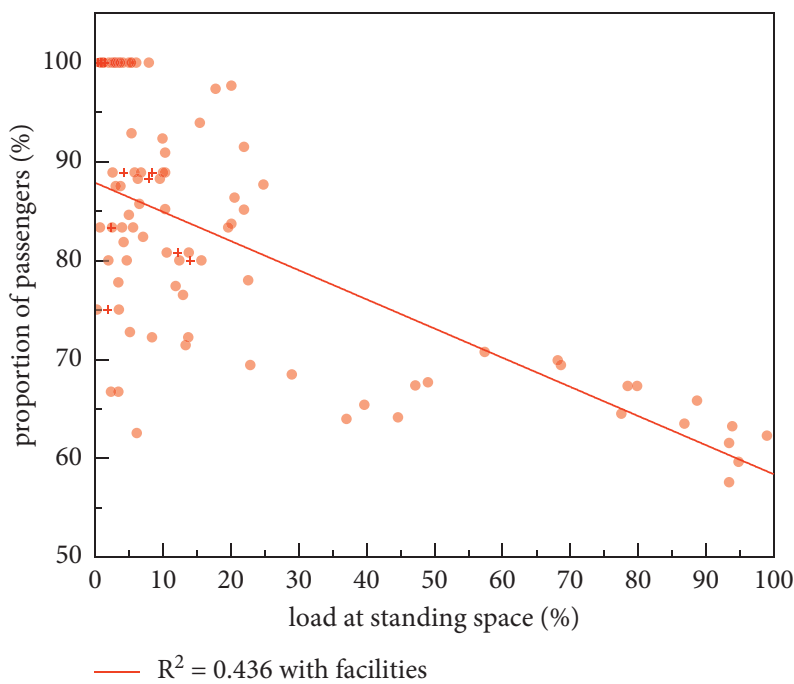

FIGURE 8: Changes in the proportion of passengers with facilities.

process. The larger the regression coefficient, the stronger the service capacity.

Similarly, an explanatory model: $K_{i}=k_{0}+k_{1} L$, is used to estimate the change in the proportion of passengers using the facility. $K_{i}$ is the proportion of passengers using a certain facility among passengers with facilities. $k_{0}$ and $k_{1}$ represent constant term and regression coefficient. The detailed model is shown in Table 7.

With the increase of load at standing space, the number of passengers in facilities with a negative regression coefficient is increasing (Figure 9), but the proportion of passengers is decreasing. The higher the service capacity of the facilities, the higher the proportion (Figure 10).

We calculated the proportion of passengers of the same gender in different facilities. Then, we compared the data in the same facility obtained for different genders (Figure 11). There is a statistical difference in the use of crossbars $(z=-5.488, p<0.001)$, rings $(z=-4.596, p<0.001)$, and posts $(z=-4.487, p<0.001)$ by passengers of different genders. There is no significant difference in the use of the other four types of facilities (all $p$ values $>0.05$ ). Compared with male passengers, female passengers rarely use crossbars $(M d n=0 \%(0-19.4)$ vs. $M d n=0 \%)$ and rings $(M d n=9.1 \%$ $(0-21.5)$ vs. $M d n=0 \%(0-16.6))$ even if they are considered to be the most important grip facilities; however, there are more female passengers who use posts than male ones $(M d n=22.5 \%(12.7-38.9)$ vs. $M d n=9.2 \%(0-22.2))$.

\section{Discussion}

This study focuses on the occupancy behavior of passengers in subway cabins and a review on availability of standardized subway cabins in China. The investigation was conducted in the early peak time of Chengdu Metro and provided more comprehensive load data for the study. The new situations observed may be unique to developing countries, including the area distribution of passengers in the cabin, selection of seats, and use of facilities. For the whole cabin, the maximum 


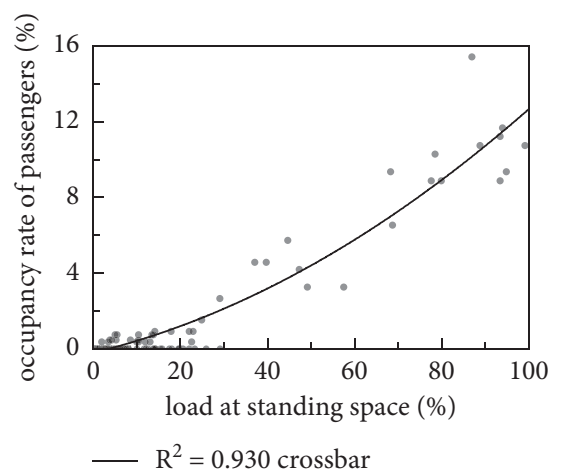

(a)

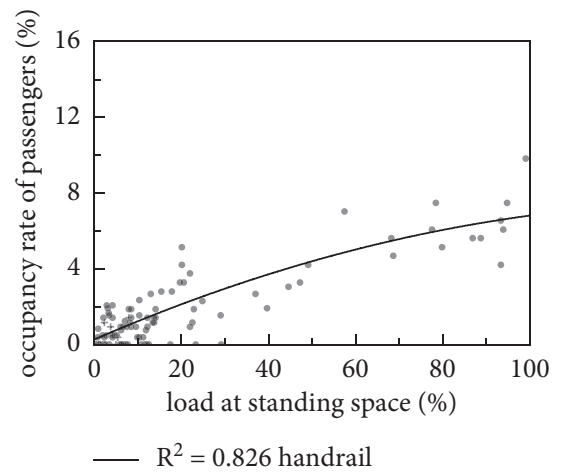

(d)

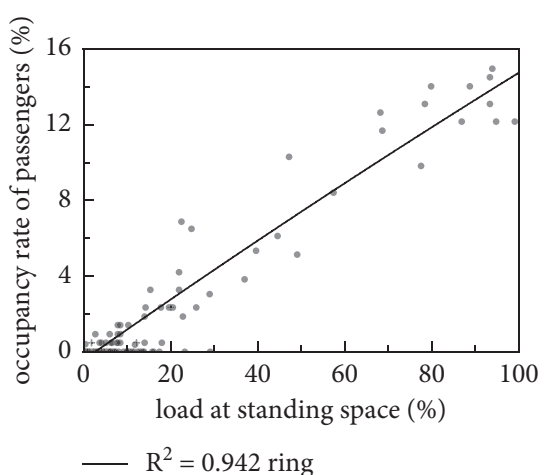

(b)

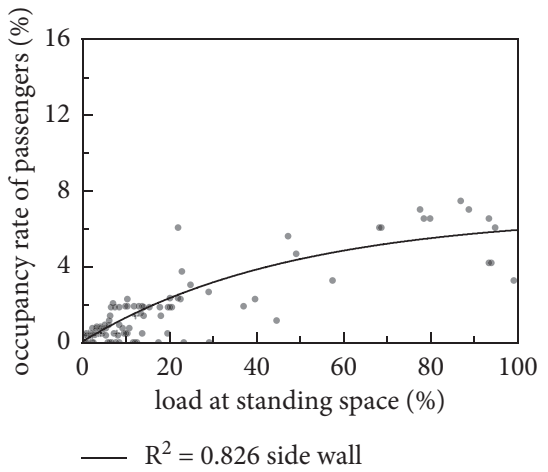

(e)

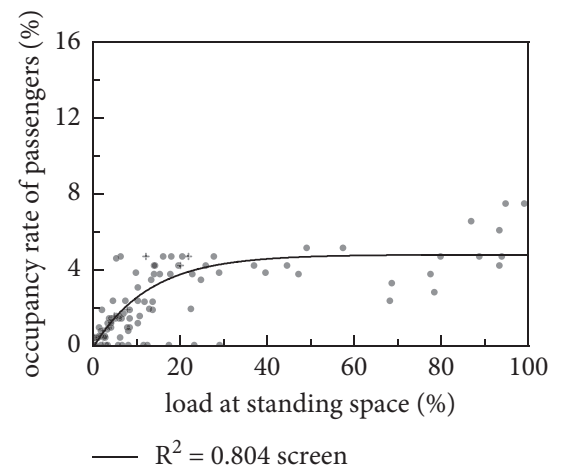

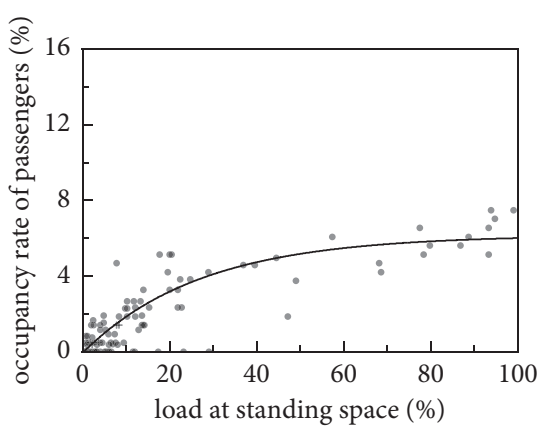

— $\mathrm{R}^{2}=0.853$ post

(c)

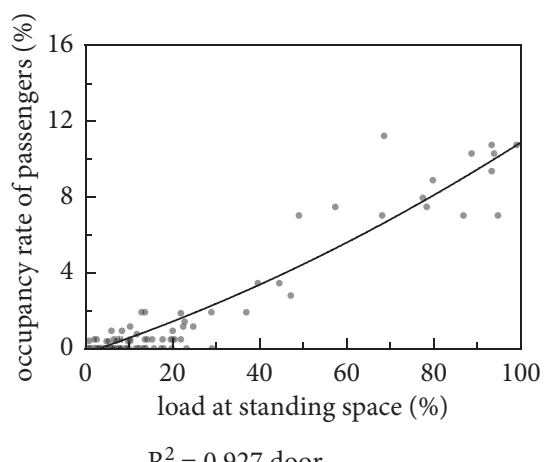

(f)

(g)

FIGURE 9: Growth curve of occupancy of standing space by passengers using different auxiliary standing facilities. (a-g) Load at standing space (\%).

occupancy of $99.1 \%$ standing space indicates that the passenger capacity of the cabin is close to 6 pass $/ \mathrm{m}^{2}$ when the cabin is crowded, which exceeds the "unacceptable crowding levels" defined by Europe $\left(4\right.$ pass $\left./ \mathrm{m}^{2}\right)$ and the United States $\left(5 \mathrm{pass} / \mathrm{m}^{2}\right)$. It is shown by the occupancy rate of $11.1 \%$ of the median standing space that the density of passengers in most sections is only about 0.7 pass $/ \mathrm{m}^{2}$, which is not that crowded.

5.1. How to Use the Cabin. The passengers at the end of the cabin had a rapid growth, exceeding $140 \%$ of the occupancy rate at the extreme, which is equivalent to the passenger density of 8.4 pass $/ \mathrm{m}^{2}$, which makes the area the most crowded area in the cabin, which is consistent with the description of Fried and DeFazio [35]. As the load at standing space increases, the end of the cabin maintains the highest occupancy rate of area, implying that the end of the cabin is the most crowded area from beginning to end. Most of the time, there is no difference in the degree of congestion between the door area and the middle area $(p>0.05)$. However, in terms of numbers, a large proportion of passengers prefer to stay in the door area, which is similar to Hirsch and Thompson's [18] conclusion. When the load at standing space is smaller, the proportion of passengers in the door area is larger (Table 5). Because the door area is larger than the end of the cabin, it is not as crowded. When the load at standing space increases, the proportion of passengers in the middle area will increase rapidly. This suggests that new passengers getting on are more likely to choose the middle area when they feel crowded in the door area. The number of 
TABLE 6: Prediction model of occupancy rate of facility.

\begin{tabular}{lcccccccc}
\hline \multirow{2}{*}{$F_{i}$} & \multicolumn{3}{c}{ Regression model } & & \multicolumn{3}{c}{ Significance test } \\
& $n_{0}$ & $n_{1}$ & $S E$ & Adjusted $R^{2}$ & df & $F$ value & $t$ & $p$ value \\
\hline Crossbar & -0.006 & 0.119 & 0.004 & 0.912 & 112 & 1052.07 & 32.43 \\
Ring & -0.004 & 0.153 & 0.004 & 0.942 & 112 & 1670.35 & 40.87 & $<0.001^{* *}$ \\
Post & 0.007 & 0.069 & 0.004 & 0.762 & 112 & 327.45 & 18.09 & $<0.001^{* *}$ \\
Handrail & 0.005 & 0.070 & 0.003 & 0.814 & 112 & 447.85 & 21.16 \\
Side wall & 0.005 & 0.065 & 0.003 & 0.783 & 112 & 368.32 & 19.19 \\
Door & -0.004 & 0.106 & 0.003 & 0.920 & 112 & 1181.63 & 34.37 & $<0.001^{* *}$ \\
Screen & 0.011 & 0.054 & 0.005 & 0.578 & 112 & 140.69 & 11.86 & $<0.001^{* *}$ \\
\hline
\end{tabular}

Note. ${ }^{*} p<0.05 ;{ }^{* *} p<0.01$.

TABLE 7: Explanatory model of the proportion of facilities in use.

\begin{tabular}{|c|c|c|c|c|c|c|c|c|}
\hline \multirow{2}{*}{$F_{i}$} & \multicolumn{3}{|c|}{ Regression model } & \multicolumn{5}{|c|}{ Significance test } \\
\hline & $n_{0}$ & $n_{1}$ & $S E$ & Adjusted $R^{2}$ & $\mathrm{df}$ & $F$ value & $\mathrm{t}$ & $p$ value \\
\hline Crossbar & 0.015 & 0.203 & 0.019 & 0.544 & 112 & 110.63 & 10.51 & $<0.001^{* *}$ \\
\hline Ring & 0.065 & 0.222 & 0.049 & 0.174 & 112 & 20.41 & 4.51 & $<0.001^{* *}$ \\
\hline Post & 0.207 & -0.107 & 0.063 & 0.020 & 112 & 2.85 & -1.688 & 0.095 \\
\hline Handrail & 0.190 & -1.03 & 0.069 & 0.013 & 112 & 2.23 & -1.49 & 0.138 \\
\hline Side wall & 0.177 & -0.091 & 0.051 & 0.023 & 112 & 3.17 & -1.78 & 0.078 \\
\hline Door & 0.033 & 0.160 & 0.041 & 0.131 & 112 & 14.90 & 3.86 & $<0.001^{* *}$ \\
\hline Screen & 0.314 & -0.278 & 0.074 & 0.125 & 112 & 14.20 & -3.76 & $<0.001^{* *}$ \\
\hline
\end{tabular}

Note. ${ }^{*} p<0.05 ;{ }^{* *} p<0.01$.

people in the middle area will exceed the end of the cabin when the load at standing space is greater than $76.7 \%$, but it will not be more crowded than the end. In addition, although the impact of gender on the choice of standing position has not been reported, it was observed that men prefer to stand at the ends of the cabin, while women prefer to stand in the door areas. In the face of crowding, it may be more difficult for women to move, and they have to stay in the door area in order to ensure that they can get off on time.

When the seat occupancy rate in the subway cabin reaches $90 \%$, at least $24 \%$ of the standing space will be occupied (Figure 3), which is equivalent to the passenger density of 1.44 pass $/ \mathrm{m}^{2}$. From the study of Berkovich et al. [12], the $\mathrm{ft}^{2} /$ pass $\left(2.36 \mathrm{ft}^{2}\right.$ per standee standard of the New York Metro) is converted into pass $/ \mathrm{m}^{2}$ in this study; the seat occupancy of $90 \%$ means the standing density of about $0.71 \mathrm{pass} / \mathrm{m}^{2}$, which indicates that there are more passengers who are willing to stand in the cabin in China. There are always standing passengers from the lowest load to near saturation, which is consistent with the research of Evans and Wener [11]. In addition, some passengers choose to stand from beginning to end on their own rather than due to nonavailable seats. A more accurate explanation is that when the seat load $S=53.3 \%$, someone is just starting to stand $(L \geq 0)$, which explains the $30 \%$ of the change $\left(R^{2}=0.30\right)$. Passengers' preference for seats has been a topic of interest for a long time, but there is no obvious difference in the layout (longitudinal and transverse) and position (by window and along the passage) of seats in terms of occupancy behaviors. Facing an increase in seat occupancy, passengers may have no option, which leads to different conclusions from a previous preference survey $[10,14]$. Men have an advantage in the process of occupying seats with a rapid growth in the early stage and can get more seats, but the proportion of passengers with seats among men is smaller than that of women. There are more women with seats, and almost only women can get seats when the occupancy is more than 95\% (Figure 6). The analysis shows that women are smaller than men, so they are more likely to get one to two extra seating spaces in case of longitudinal seating layout space.

For passengers standing in the cabin, auxiliary facilities are very important in maintaining the body balance of vehicles during longitudinal acceleration [45] and emergency braking [46], which reduces the injury degree in collision [47] and improves the comfort degree [48]. In this study, all the facilities that can provide support for the body are included in the statistics. More than $40 \%$ of standing passengers do not use facilities during the most crowded period. When the load at standing space increases, the proportion of passengers with facilities decreases (Figure 8). It is very dangerous in a running train for the passengers who do not use any facilities but just rely on the body extrusion of other passengers to maintain their balance. The grip facilities in the cabin can provide enough grip strength to avoid the danger caused by body imbalance [49], but they are not the ones that passengers tend to use, especially the crossbars and rings. Although many passengers choose to use the posts, more passengers rely on the posts rather than grasping them when the cabin is not that crowded. Similarly, facilities that provide physical support have a higher occupancy frequency by passengers, because relying on makes the body more comfortable [34]. Any facility that needs to be used with high arms is not favored by passengers, especially women, which is consistent with the research of Kobayshi [36]. However, facilities with low occupancy frequency, such 


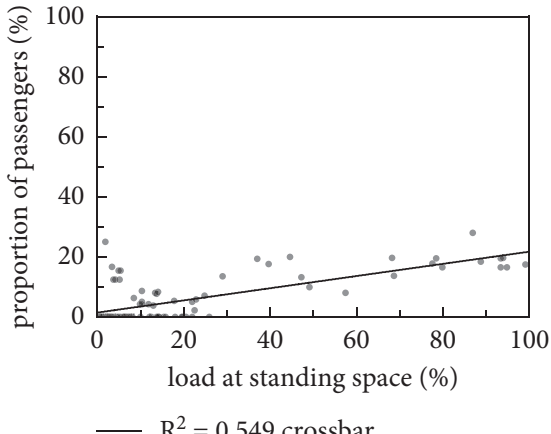

(a)

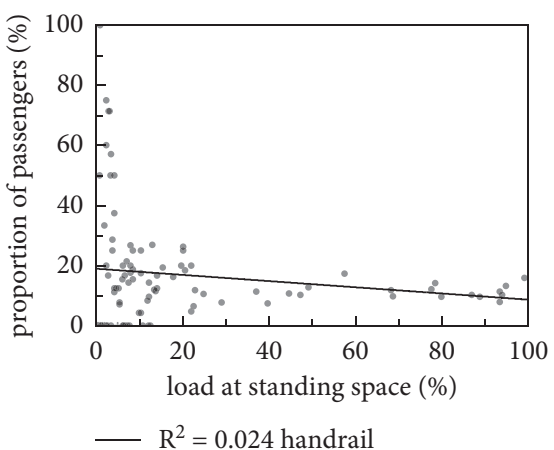

(d)

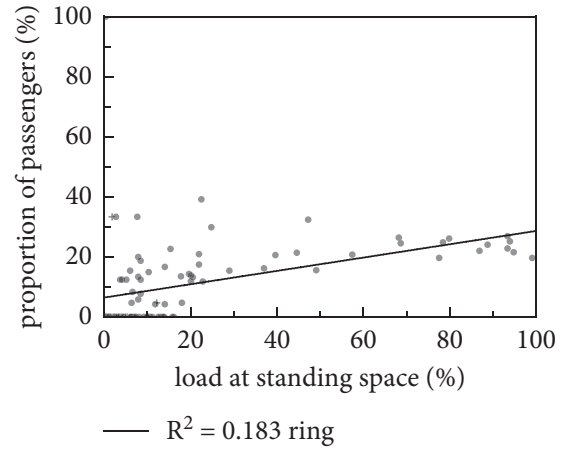

(b)

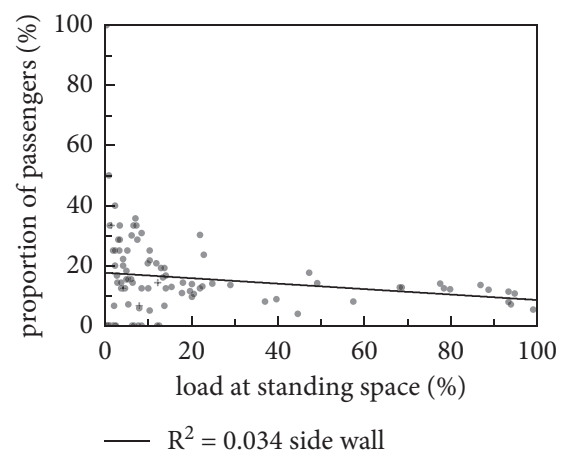

(e)

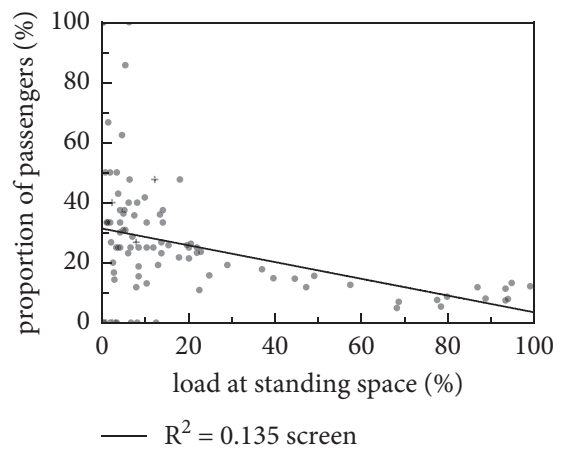

(g)

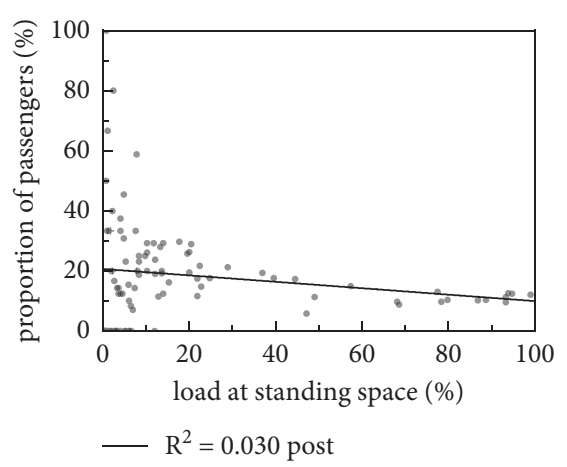

(c)

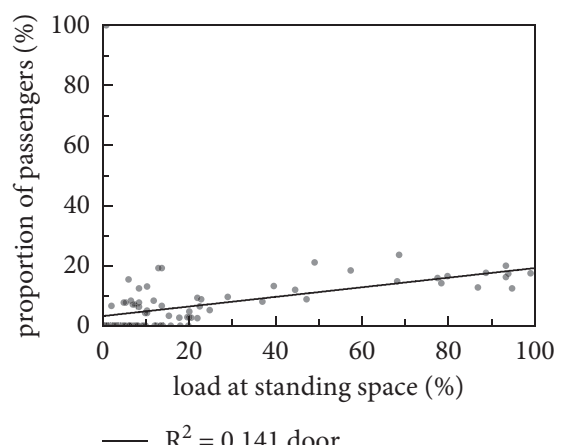

(f)

FIGURE 10: Changes in the proportion of passengers using different auxiliary standing facilities.

as rings, doors, and cross bars, have higher service when crowded (Figure 9). As the load at standing space increases, the proportion of passengers using these three facilities is increasing, while other facilities are decreasing (Figure 10).

5.2. Significance to Interior Design. Studying the behavior of passengers is the basis for providing optimization suggestions for the interior design of the cabins, because the designs of these cabins are standardized and exported through CRRC. These carriages are used in Rio (Lines 1, 2 and 4), Mumbai, Singapore (Thomson-East Coast Line), Buenos Aires (Line A), and other cities worldwide. At the same time, Chengdu's subway operation is also considered to have the characteristics of a typical urban rail and has universal research value $[50,51]$. The uneven distribution of passengers in the cabin aggravates the occurrence of crowding. Improving the interior design is of great help to alleviate local crowding, promote the rational utilization of the space and the efficiency of boarding and alighting, and improve operational efficiency. The middle areas of the cabins are equipped with the most crossbars and rings, but the median occupancy rate of the passengers is the lowest and the proportion of passengers without facilities is the highest. The passengers will first occupy the ends and door areas that they can rely on in face of the facilities they do not like. Therefore, the main direction of design improvement is to reduce the accumulation of passengers at the ends and door areas of the cabin, and below are some suggestions:

(i) It is necessary to install seats at the end of the cabin or install handrails on the wall to reduce the area of the side wall that can be relied on; it is necessary to extend the crossbar and ring to the ends, and it is very important to provide sufficient grasping facilities for passenger safety. 


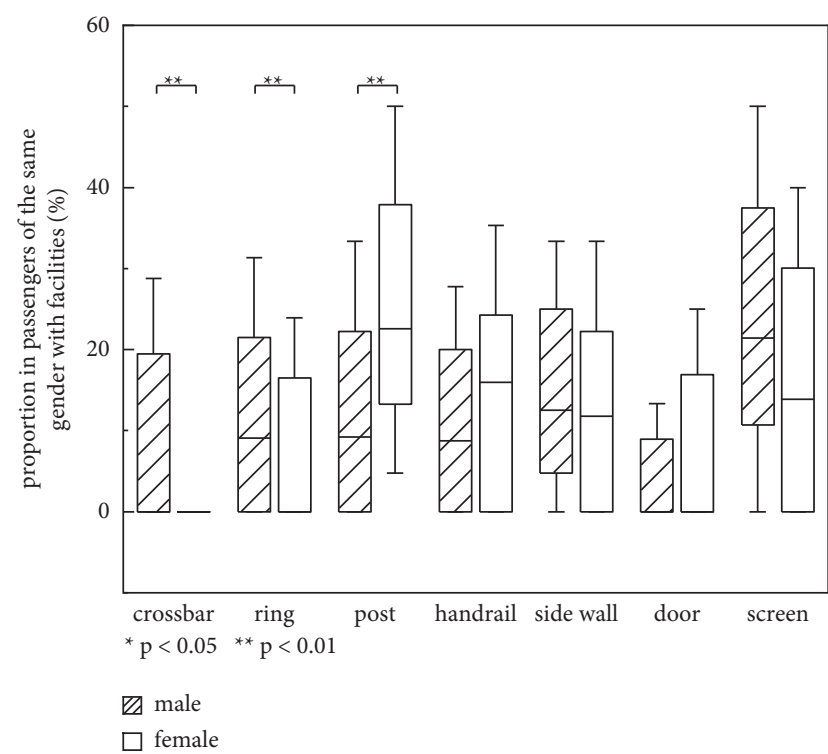

Figure 11: Differences in the use of facilities between different genders.

(ii) Door areas are where passengers can board and alight, so the first consideration is to remove the central post, which provides limited service capacity and may attract passengers to gather in the door area, so as to avoid passengers staying here as much as possible. Besides, the current screen design shall be improved by removing the glass partition, which can avoid passengers leaning on both sides of the door and help to blur the boundary between the door area and the middle area as well. It is recommended to install circular handrails on the roof of the door area.

(iii) For the middle area, it is encouraged to keep the crossbars and pole on the central axis of the cabin. In the cabins with transverse seats (Figure 1(c)), the crossbars close to the seats shall also be cancelled to make passengers use the facilities on the central axis of the cabin as much as possible.

But there are still some problems that cannot be solved by improving the design. For example, passengers need to have enough safety awareness to stop leaning on the door. The overcrowding phenomenon of seats may be useful to divide the longitudinal seats, but it is more important for passengers to realize that the occupancy behavior is inappropriate after load saturation.

5.3. Limitations and Future Research. The types and behaviors of passengers are quite complex in the cabin. The workload of the observers must be considered to ensure the accuracy of the data quality, so it is impossible to collect more types of data in this work, such as recording whether the passengers are elderly or children and whether the passengers carry luggage and observing the disabled. The data observed cannot explain personal factors such as passengers' tolerance to crowding. While emphasizing rational analysis, passengers' views on the characteristics of the cabin may be ignored. On the basis of natural observation, we will further consider the subjective intentions of the passengers. For example, the subjective preference data of passengers can be combined to explain the occupancy of facilities and locations, not just seats; in addition, the paper uses cross-sectional data for analysis, with the purpose of restoring the current situation of the use of the cabin. We will conduct regular surveys in the future to reveal changes in passenger demand and the behavior in the context of capacity growth.

\section{Conclusions}

This study observed how subway passengers fill into and use the cabin, including the areas, seats, and auxiliary standing facilities. It is shown by the results that (1) the load of each standing area is uneven in the cabin, and the end of the cabin will exceed the load. Males are more distributed at the end of the cabin, while females are in the door area; (2) there is also an overload in seats, but there is no difference in the occupancy of seat types; (3) as the load at standing space increases, the proportion of passengers with facilities is declining, and the proportion of passengers without facilities in the middle area is the largest; (4) facilities with strong service capabilities are not favored by passengers and there is a significant difference in the occupation of facilities between men and women. It is hoped that this research can provide experience of improvement to the interior design of the cabin, and practical measures were proposed. In the long run, this research will become more meaningful through reasonable planning of the subway network, the use of flexible marshalling mode, and scientific timetables.

\section{Data Availability}

The data used to support the findings of this study are available from the corresponding author upon request.

\section{Conflicts of Interest}

The authors declare that there are no conflicts of interest regarding the publication of this paper.

\section{Acknowledgments}

Thanks are due to Dr. Jian Xu, Dr. Jin Wang, Dr. Hong-Tao Chen, and Dr. Shu Feng from Southwest Jiaotong University for completing the collection of passenger data as observers in this study. The study was conducted with financial support from the National Key R\&D Program of China (2017YFB1201103-09), the Major Project of Sichuan Social Science Research Planning Base (SC20EZD056), and the Practice Base Project in the Graduate School of Southwest Jiaotong University.

\section{References}

[1] B. M. Han, Z. X. Yang, and Y. R. Yu, "Statistical analysis of urban rail transit operation in the world in 2020: a review," Urban Rapid Rail Transit, vol. 34, no. 1, pp. 5-11, 2021. 
[2] Y. Wang, Y. C. Wang, D. Ettema, Z. Mao, S. G. Charlton, and H. Zhou, "Commuter value perceptions in peak avoidance behavior: an empirical study in the Beijing subway system," Transportation Research Part A: Policy and Practice, vol. 139, pp. 70-84, 2020.

[3] M. Zhou, H. Dong, F.-Y. Wang, Y. Zhao, S. Gao, and B. Ning, "Field observations and modeling of waiting pedestrian at subway platform," Information Sciences, vol. 504, pp. 136-160, 2019.

[4] S. Seriani and R. Fernandez, "Pedestrian traffic management of boarding and alighting in metro stations," Transportation Research Part C: Emerging Technologies, vol. 53, pp. 76-92, 2015.

[5] X. Wan, P. M. Schonfeld, and Q. Li, "What factors determine metro passengers' risky riding behavior? An approach based on an extended theory of planned behavior," Transportation Research Part F: Traffic Psychology and Behaviour, vol. 42, pp. 125-139, 2016.

[6] N. Shiwakoti, R. Tay, P. Stasinopoulos, and P. J. Woolley, "Likely behaviours of passengers under emergency evacuation in train station," Safety Science, vol. 91, pp. 40-48, 2017.

[7] J. Li and X. Wang, "Multimodal evacuation after subway breakdown: a modeling framework and mode choice behavior," Transportation Research Interdisciplinary Perspectives, vol. 6, Article ID 100177, 2020.

[8] T. Niederkrotenthaler, G. Sonneck, K. Dervic et al., "Predictors of suicide and suicide attempt in subway stations: a population-based ecological study," Journal of Urban Health, vol. 89, no. 2, pp. 339-353, 2012.

[9] A. Uittenbogaard and V. Ceccato, "Temporal and spatial patterns of suicides in Stockholm's subway stations," Accident Analysis \& Prevention, vol. 81, pp. 96-106, 2015.

[10] M. Wardman and P. Murphy, "Passengers' valuations of train seating layout, position and occupancy," Transportation Research Part A: Policy and Practice, vol. 74, pp. 222-238, 2015.

[11] G. W. Evans and R. E. Wener, "Crowding and personal space invasion on the train: please don't make me sit in the middle," Journal of Environmental Psychology, vol. 27, no. 1, pp. 90-94, 2007.

[12] A. Berkovich, A. Lu, B. Levine, and A. V. Reddy, "Observed customer seating and standing behavior and seat preferences on board subway cars in New York City," Transportation Research Record: Journal of the Transportation Research Board, vol. 2353, no. 1, pp. 33-46, 2013.

[13] E. L. Miller, S. M. Lapp, and M. B. Parkinson, "The effects of seat width, load factor, and passenger demographics on airline passenger accommodation," Ergonomics, vol. 62, no. 2, pp. 330-341, 2019.

[14] T. O’Malley and M. Vaishnav, “Is this seat taken?" Transportation Research Record: Journal of the Transportation Research Board, vol. 2419, no. 1, pp. 33-39, 2014.

[15] C. Aceves-González, A. May, and S. Cook, “An observational comparison of the older and younger bus passenger experience in a developing world city," Ergonomics, vol. 59, no. 6, pp. 840-850, 2016.

[16] A. N. Kenner and G. Katsimaglis, "Gender differences in proxemics: taxi-seat choice," Psychological Reports, vol. 72, no. 2, pp. 625-626, 1993.

[17] TRB, "Transit Capacity And Quality Of Service Manual, Transit Cooperative Research Program," , pp. 3-29, Transport Research Board (TRB), Washington, D.C., USA, 2003, TCRP Report 100, 2nd edition.

[18] L. Hirsch and K. Thompson, "I can sit but I'd rather stand: commuter's experience of crowdedness and fellow passenger behaviour in carriages on Australian metropolitan trains," in Proceedings of the 34th Australasian Transport Research Forum(ATRF) Proceedings, Australia, Oceania, September 2011.

[19] Beijing Municipal Planning Commission, GB 50157-2013 Code For Design Of Metro, Beijing Municipal Planning Commission, Beijing, china, 2013.

[20] L. A. Hoel, N. J. Garber, and A. W. Sadek, “Transportation Infrastructure Engineering," A Multimodal Integration, SI Version, Cengage Learning, Boston, MA, USA, 2010.

[21] M. Batarce, J. C. Muñoz, J. de Dios Ortúzar, S. Raveau, C. Mojica, and R. A. Ríos, "Use of mixed stated and revealed preference data for crowding valuation on public transport in Santiago, Chile," Transportation Research Record: Journal of the Transportation Research Board, vol. 2535, no. 1, pp. 73-78, 2015.

[22] G. Whelan and J. Crockett, "An investigation of the willingness to pay to reduce rail overcrowding," in Proceedings of the 1st International Conference on Choice Modelling, Harrogate, England, April 2009.

[23] M. Wardman and G. Whelan, "Twenty years of rail crowding valuation studies: evidence and lessons from British experience," Transport Reviews, vol. 31, no. 3, pp. 379-398, 2011.

[24] N. D. Mohd Mahudin, T. Cox, and A. Griffiths, "Measuring rail passenger crowding: scale development and psychometric properties," Transportation Research Part F: Traffic Psychology and Behaviour, vol. 15, no. 1, pp. 38-51, 2012.

[25] A. Tirachini, R. Hurtubia, T. Dekker, and R. A. Daziano, "Estimation of crowding discomfort in public transport: results from Santiago de Chile," Transportation Research Part A: Policy and Practice, vol. 103, pp. 311-326, 2017.

[26] B. Wang and J. Zacharias, "Noise, odor and passenger density in perceived crowding in public transport," Transportation Research Part A: Policy and Practice, vol. 135, pp. 215-223, 2020.

[27] P. L. D. O. Costa Neto and C. M. D. D. Santos, "Aspectos ergonômicos e estatísticos no projeto de um carro do metrô," Gestão \& Produção, vol. 9, no. 1, pp. 93-105, 2002.

[28] S. Coxon, K. Burns, A. de Bono, and R. Napper, "An examination of three approaches to metro rolling stock design to ameliorate extended dwell times due to passenger growth and associated crowding," in Proceedings of the 34th Australasian Transport Research Forum(ATRF) Proceedings, Adelaide, Australia, September 2011.

[29] R. Thoreau, C. Holloway, G. Bansal, K. Gharatya, T. R. Roan, and N. Tyler, "Train design features affecting boarding and alighting of passengers," Journal of Advanced Transportation, vol. 50, no. 8, pp. 2077-2088, 2016.

[30] L. C. Oliveira, C. Fox, S. Birrell, and R. Cain, "Analysing passengers' behaviours when boarding trains to improve rail infrastructure and technology," Robotics and Computer-Integrated Manufacturing, vol. 57, pp. 282-291, 2019.

[31] N. Luangboriboon, S. Seriani, and T. Fujiyama, "The influence of the density inside a train carriage on passenger boarding rate," International Journal of Reality Therapy, vol. 9, no. 5, pp. 445-460, 2020.

[32] S. A. Regirer and D. S. Shapovalov, "Filling space in public transport by passengers," Automation and Remote Control, vol. 64, no. 8, pp. 1301-1309, 2003.

[33] L. Hirsch, K. Thompson, and D. Every, "Frustrations, fights, and friendships: the physical, emotional, and behavioural effects of high-density crowding on Mumbai's suburban rail passengers," Qualitative Report, vol. 22, no. 2, pp. 550-567, 2017. 
[34] K. Thompson, L. Hirsch, and S. Rainbird, A Socio-Economic Study of Carriage and Platform Crowding in the Australian Railway Industry: Qualitative Research Summary, CRC for Rail Innovation \& University of South Australia, Brisbane, Australia, 2011.

[35] M. L. Fried and V. J. DeFazio, "Territoriality and boundary conflicts in the subway," Psychiatry, vol. 37, no. 1, pp. 47-59, 1974.

[36] T. Kobayshi, "Sexual differences in posture-related human behavior on subway trains, and their biological function," Journal of Ethology, vol. 12, no. 2, pp. 121-130, 1994.

[37] London Assembly Transport Committee, The Big Squeeze: Rail Overcrowding in London, Greater London Authority, London, England, 2009.

[38] Z. Li and D. Hensher, "Crowding in public transport: a review of objective and subjective measures," Journal of Public Transportation, vol. 16, no. 2, pp. 107-134, 2013.

[39] A. Tirachini, D. A. Hensher, and J. M. Rose, "Crowding in public transport systems: effects on users, operation and implications for the estimation of demand," Transportation Research Part A: Policy and Practice, vol. 53, pp. 36-52, 2013.

[40] A. Puong, Dwell Time Model and Analysis for the MBTA Red Line, Massachusetts Institute of Technology Research Memo, Cambridge, MA, USA, 2000.

[41] R. Fernandez, "Experimental study of bus boarding and alighting times," in Proceedings of the European Transport Conference, Glasgow, Scotland, UK, October 2011.

[42] J. Çapalar, A. Nemec, C. Zahradnik, and C. Olaverri-Monreal, "Optimization of passenger distribution at metro stations through a guidance system," in Proceedings of the International Conference on Computer Aided Systems Theory, pp. 397-404, Las Palmas, Spain, February 2018.

[43] B. L. Paterson, J. L. Bottorff, and R. Hewat, "Blending observational methods: possibilities, strategies, and challenges," International Journal of Qualitative Methods, vol. 2, no. 1, pp. 29-38, 2003.

[44] A. Willis, N. Gjersoe, C. Havard, J. Kerridge, and R. Kukla, "Human movement behaviour in urban spaces: implications for the design and modelling of effective pedestrian environments," Environment and Planning B: Planning and Design, vol. 31, no. 6, pp. 805-828, 2004.

[45] T. A. Sarraf, D. S. Marigold, and S. N. Robinovitch, "Maintaining standing balance by handrail grasping," Gait \& Posture, vol. 39, no. 1, pp. 258-264, 2014.

[46] T. Robert, P. Beillas, A. Maupas, and J.-P. Verriest, "Conditions of possible head impacts for standing passengers in public transportation: an experimental study," International Journal of Crashworthiness, vol. 12, no. 3, pp. 319-327, 2007.

[47] S. Yao, X. Li, X. Xiao, P. Xu, and Q. Che, "Injuries to standing passengers using different handrails in subway train collision accidents," International Journal of Crashworthiness, vol. 26, no. 1, pp. 53-64, 2019.

[48] B. Guo, W. Gan, and W. Fang, "Using hand grip force as a correlate of longitudinal acceleration comfort for rapid transit trains," Sensors, vol. 15, no. 7, pp. 15755-15771, 2015.

[49] J. P. Powell and R. Palacín, "Passenger stability within moving railway vehicles: limits on maximum longitudinal acceleration," Urban Rail Transit, vol. 1, no. 2, pp. 95-103, 2015.

[50] Y. Chen, B. Yi, Y. Jiang, J. Sun, and M. I. M. Wahab, "Interarrival time distribution of passengers at service facilities in underground subway stations: a case study of the metropolitan city of Chengdu in China," Transportation Research Part A: Policy and Practice, vol. 111, pp. 227-251, 2018.

[51] W. Huang, B. Shuai, Y. Sun, Y. Wang, and E. Antwi, "Using entropy-TOPSIS method to evaluate urban rail transit system operation performance: the China case," Transportation Research Part A: Policy and Practice, vol. 111, pp. 292-303, 2018. 